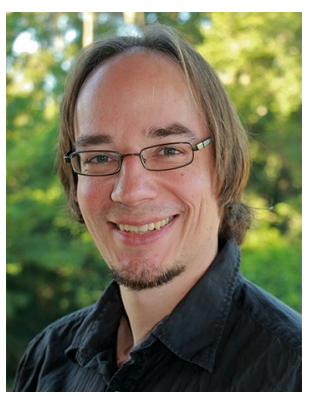

\title{
Social media science communication is a nonstop academic conference for all
}

\author{
Jens Foell recently changed careers and began working fulltime for maiLab, Germany's biggest \\ science communication YouTube channel. In this World View, he shares his experiences as a \\ science communicator and discusses the advantages and challenges.
}

Credit: Marisa Benz

S cientific meetings are essential to research, providing a framework for rapid communication and exchange that cannot be matched by the scientific publishing process. They are also important hubs for social interactions, with often life-long friendships and professional collaborations emerging among researchers. At the same time, science journalists use these meetings to learn about latest developments to report to the general public.

So it seems odd that many scientists do not seem interested in, or even aware of, the large-scale academic conference that is taking place right under their noses.

I am referring to science communication (or 'sci comm') on social media, which consists of statements and exchanges that fulfill all the functions of academic meetings described above. Researchers post lab equipment on Instagram, methods tutorials on YouTube, commentaries on Twitter. They answer questions on ResearchGate, post job offerings on LinkedIn, and summarize their findings on TikTok. In addition, new features that can be used for novel ways of broadcasting keep being introduced and implemented on existing platforms, such as Snapchat and Clubhouse. Taken together, the last years have seen the online emergence of the entire spectrum of personal and professional scientific exchanges usually found at academic conferences. With one striking difference: the public, which is traditionally excluded from scientific meetings, is listening in. And not only that: as social media are built to facilitate interaction, many of the audience are commenting and asking questions.

The COVID-19 pandemic has catalyzed this development to a dizzying degree. Countless people of all ages had a strong motivation to learn basic and advanced elements of epidemiology, virology, immunology, molecular biology, and the general workings of the scientific process, and many turned to social media for information. Luckily, a solid number of knowledgeable researchers saw it as their duty to use their valuable personal time to communicate their science to the interested public, and some of them gained a large following by doing so. (Less luckily, the same can be said for some charlatans spreading misinformation.) Once the pandemic is over, the landscape of science communication will have shifted towards social media in an unprecedented manner.

While these changes pose considerable challenges, the development also brings with it exciting new opportunities, one example being the increase in accessibility and inclusivity on display. In contrast to scientific meetings, neither travel funding nor group membership are required to take part in the academic exchange on social media. Young students contemplating possible career paths today have a plethora of ways to find information on prospective fields, as well as advice and encouragement, and are often able to identify and contact relevant researchers within minutes. In essence, communicated science is becoming more widely accessible and, as such, more relevant to society.

This rising awareness and relevance of science communication has certainly left an impression on me as a researcher. Just like many other scientists, I grew up learning about science through educational TV programming and non-fiction books. However, it was only as an adult working in research that I realized the importance of this type of public outreach. Furthermore, this new focus on communication felt more like a calling than a burden to me. So, after having worked in brain imaging for more than a decade, in 2020 I moved countries and changed careers in order to be a full-time science communicator. I was lucky enough to find a position in the most successful sci comm team in my country, consisting mostly of $\mathrm{PhD}$-level former researchers and with more than a million regular viewers. My main motivation for this drastic change in direction, and for taking the risks that come with it, was the notion that science communication is presently still less supported, less accepted, and less developed than scientific research itself. I will be glad to spend the rest of my working days attempting to remedy this.

One personal reason for doing so is that I want to inspire future researchers the way that the sci comm of my youth inspired me. At the same time, I now realize the flaws of these earlier projects, such as an embarrassing lack of diverse voices, which pushes me to try and improve, rather than replicate, the past sci comm efforts that I enjoyed and respected. One thing that I firmly believe is: if the average member of the general public can only name white male scientists, or attributes to them the findings and successes of women and minorities, this is as much (or more) a failure of science communication as one of science itself. Every time a scientist stands in front of a camera, or of an elementary school class, or goes online on a public forum, they represent not only their own research, but also science and academia in general. A big part of my motivation in sci comm is to reflect upon this responsibility and how it has helped me evolve my own views about the scientific establishment.

Just like other academic conferences, the continuous one on social media can seem intimidating and exhausting if you don't have any contacts or don't know your way around. But just like with the others, by the time you leave the meeting you're often inspired by the people you've met, the presentations you've seen, and the new methods you've heard about. I think it's time for you to drop by.

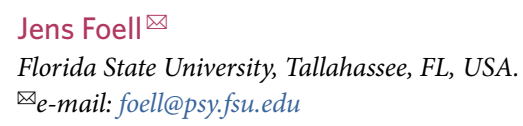

Published online: 26 May 2021 https://doi.org/10.1038/s41562-021-01138-0

Competing interests

Jens Foell is also a freelance science communication trainer. 